\title{
Testing the Efficacy of INSIGHTS on Student Disruptive Behavior, Classroom Management, and Student Competence in Inner City Primary Grades
}

\author{
Sandra Graham McClowry • David L. Snow • \\ Catherine S. Tamis-LeMonda $\cdot$ Eileen T. Rodriguez
}

Published online: 31 December 2009

(C) The Author(s) 2009. This article is published with open access at Springerlink.com

\begin{abstract}
A prevention trial tested the efficacy of INSIGHTS into Children's Temperament as compared to a Read Aloud attention control condition in reducing student disruptive behavior and enhancing student competence and teacher classroom management. Participants included 116 first and second grade students, their parents, and their 42 teachers in six inner city schools. Teachers completed the Sutter-Eyberg Student Behavior Inventory (SESBI) and the Teacher's Rating Scale of Child's Actual Competence and Social Acceptance (TRS) at baseline and again upon completion of the intervention. Boys participating in INSIGHTS, compared with those in the Read Aloud program, showed a significant decline in attentional difficulties and overt aggression toward others. Teachers in INSIGHTS, compared to those in the attention control condition, reported significantly fewer problems managing the emotional-oppositional behavior, attentional difficulties, and covert disruptive behavior of their male students. They also perceived the boys as significantly more cognitively and physically competent.
\end{abstract}

S. G. McClowry ( $\square)$

Departments of Applied Psychology and Teaching and Learning, Steinhardt School of Culture, Education and Human Development, New York University, 246 Greene Street, 507 W, New York, NY 10003, USA

e-mail: sandee.mcclowry@nyu.edu

D. L. Snow

The Consultation Center and Division of Prevention and Community Research, Yale University School of Medicine, New Haven, CT, USA

C. S. Tamis-LeMonda · E. T. Rodriguez

Department of Applied Psychology, Steinhardt School of Culture, Education and Human Development, New York University, New York, NY, USA
Keywords Teachers - Temperament · Prevention . Classroom management

Left untreated, disruptive student behavior in the primary grades ripples through the classroom, generating an array of immediate and long-term negative consequences. Students who are disruptive spend less time engaged in academic activities and have fewer positive interactions with their peers and teachers (Evertson \& Weinstein, 2006; Shinn, Ramsey, Walker, Stieber, \& O'Neill, 1987). Over time, a developmental cascade occurs among such children; negative functioning in one domain spills over and compromises other areas of functioning (Masten et al., 2005). As multiple studies have revealed, disruptive behavior in the primary grades marks the beginning of a pathway that, for many children, leads progressively to more serious social, behavioral, and academic problems (Schaeffer et al., 2006; Tremblay, Pihl, Vitaro, \& Dobkin, 1994).

Without intervention, disruptive student behavior dramatically escalates during the elementary school years and negatively affects not only the involved students but also their peers (Guerra \& Smith, 2006). In elementary school classrooms in which a number of pupils are disruptive, such behavior becomes normative and leads to even higher levels of classroom behavior problems (Barth, Dunlap, Dane, Lochman, \& Wells, 2004). Disruptive student behavior is of particular concern in inner city classrooms, which include disproportionate numbers of economically disadvantaged students. Due to a multitude of adverse circumstances, children living in poverty are at greater risk for developing disruptive behavior problems (Dubrow \& Ioppolito, 1994; Institute of Medicine, 1994; Kellam, Ling, Merisca, Brown, \& Ialongo, 1998). 
Schools are ideal locations for offering preventive interventions because they can reach a large number of children in a context in which they spend a considerable amount of their daily lives. To date, however, only a few interventions have focused on reducing the disruptive behavior of at-risk children in early elementary education classrooms (Catalano, Berglund, Ryan, Lonczak, \& Hawkins, 2002; Greenberg et al., 2003). A notable exception is a prevention study conducted in urban classrooms in which teachers engaged first and second grade students in the Good Behavior Game (Dolan et al., 1993; Kellam et al., 1998). The goal of the intervention was to socialize children to regulate their own behavior and that of their classmates through interdependent team activities. Compared to matched control schools, the intervention enhanced the classroom management skills of the teachers and reduced the disruptive behavior of their students, particularly among males.

The Fast Track Project, a school-based efficacy trial, was conducted in four communities characterized by high levels of poverty and violence (Conduct Problems Prevention Research Group, 2002). Demographically-matched schools were randomly assigned to a control condition or to an intervention condition with seven integrated programs. The teacher-led PATHS curriculum was implemented in primary grade classrooms as a universal intervention aimed at enhancing the social competence and anger management skills of students. Additional parenting and social skills programs were provided to a select subgroup of children who were identified in kindergarten as exhibiting disruptive behaviors. The "targeted" children in the intervention schools, compared to those in the control condition, demonstrated fewer behavior problems by the end of first grade. Furthermore, teacher reports obtained when the children were in the third grade support the long-term benefits of the intervention, with declines in disruptive behavior being sustained over time.

Another preventive intervention focused on primary grade children from three communities, a majority of which were from Hispanic families (Barrera et al., 2002). Students who exhibited aggressive behavior or reading difficulties were randomly assigned to a multi-component intervention or a control group. Compared to their matched controls, the children who benefited most from the intervention were those who initially demonstrated higher levels of aggressive behavior.

Collectively, these interventions provide compelling evidence that preventive intervention can be effective in reducing the behavior problems of at-risk students in the early elementary grades. Meta-analyses confirm that children with higher levels of behavioral problems at baseline are the most likely to improve (Wilson, Gottfredson, \& Najaka, 2001; Wilson, Lipsey, \& Derzon,
2003). Aggressive behavior, however, is often confounded with gender. In general, boys exhibit more disruptive behavior than girls (Broidy et al., 2003; Coie \& Dodge, 1998; Eccles \& Blumenfeld, 1985), a finding that extends to the classroom setting (Kellam et al., 1998; Molins \& Clopton, 2002). In response to their misbehavior, teachers interact more with their male students than their female students. Although boys receive more attention from their teachers, the interactions tend to be managerial and negative (Jones \& Dindia, 2004; Kelly, 1988). In addition, boys are perceived by their teachers as more difficult to manage than girls (Childs \& McKay, 2001).

After conducting a meta-analysis examining gender differences in classroom interactions, Jones and Dindia (2004) concluded that other student characteristics aside from gender are likely to play a role. A burgeoning literature documents the influential role of temperament on the behavior and manageability of children (Rothbart \& Bates, 2006). Temperament is the consistent behavioral style that a child demonstrates across a variety of settings and circumstances, particularly those that involve stress or change (McClowry, 2003). It also is a lens through which individuals view their world which, in turn, influences their self-perceptions and reactions to life experiences (Rothbart \& Bates, 2006).

Descriptive studies have shown that children with temperaments high in task persistence are particularly advantaged in relation to school and social outcomes (Bramlett, Scott, \& Rowell, 2000; Guerin, Gottfried, Oliver, \& Thomas, 2003; Prior, Sanson, Smart, \& Oberklaid, 2000). In general, they behave more positively in the classroom and are perceived by their teachers as more teachable and competent (Keogh, 1994; Nelson, Martin, Hodge, Havill, \& Kamphaus, 1999; Prior et al., 2000; Rothbart \& Bates, 2006). In contrast, school-age children with temperaments low in task persistence, high in activity, and high in negative reactivity are more likely to demonstrate negative outcomes across multiple domains, including disruptive classroom behavior and poor school performance (Guerin et al., 2003; Nelson et al., 1999; Prior et al., 2000; Rothbart \& Bates, 2006).

Teachers also react to the temperaments of their students. Their evaluations of students' abilities, level of adjustment, and intelligence are highly related to their perceptions of their temperaments (Guerin et al., 2003; Keogh, 2003; Lerner, Lerner, \& Zabski, 1985; Pullis \& Cadwell, 1982). Although there are real differences in how teachers behave and respond to temperament variability, some are unaware of its effect on their interactions with students (Keogh, 2003). Such studies suggest that understanding child temperament could assist teachers in more successfully interpreting their students' behavior and enhancing classroom management. No previous studies, 
however, have tested the efficacy of temperament-based intervention in the classroom setting (McClowry, Rodriguez, \& Koslowitz, 2008).

INSIGHTS into Children's Temperament is a comprehensive temperament-based intervention for inner city primary grade classrooms. INSIGHTS is comprised of three integrated programs (McClowry, 2003). Teachers and parents attend parallel but separate workshops in which they are taught temperament-based strategies intended to both reduce the behavior problems of children and enhance their ability to self-regulate. The children's program is conducted in the classrooms of the participating teachers. Participating children and their classmates learn related content intended to enhance their empathy skills and employ problem-solving techniques when they encounter daily dilemmas.

A prior paper reported on the efficacy of INSIGHTS, compared to a Read Aloud attention control group, in reducing parent-reported child behavior problems (McClowry, Snow, \& Tamis-LeMonda, 2005). Findings demonstrated that INSIGHTS was more effective than the Read Aloud program in reducing children's behavior problems at home. INSIGHTS showed even greater efficacy among children who were at diagnostic levels of three disruptive disorders: Attention Deficit with Hyperactivity Disorder, Oppositional Defiant Disorder, and Conduct Disorder.

Using teacher data from the same prevention trial, this paper extends those findings by examining the efficacy of INSIGHTS in inner city first and second grade classrooms. Specifically, the following hypotheses were tested: The INSIGHTS intervention, as compared to a Read Aloud attention control condition, will result in significantly (1) less disruptive classroom behavior; (2) fewer teacher problems managing disruptive behaviors; and (3) enhanced teacher perceptions of student competence and peer acceptance. In addition, the efficacy of the program is expected to be greater for boys than for girls.

\section{Description of the INSIGHTS into Children's Temperament Intervention}

The conceptualization for INSIGHTS is based on temperament theory, which provides teachers, parents, and other caretakers with a framework for appreciating and supporting the individual differences of children. Temperament-based intervention aims to improve the fit between the child and his/her environment. Goodness of fit is the consonance of a child's temperament to the demands, expectations, and opportunities of the environment (Chess $\&$ Thomas, 1984). When it is achieved, competent behavior can be expected. If there is poorness of fit, however, maladaptive behavior is more likely to result.
The curriculum for the INSIGHTS teacher and parent programs has three components that are implemented over a 10 -week period during 2-hour, weekly sessions. The first, "Learning about Child Temperament," focuses on the 3 Rs: Recognize, Reframe, and Respond. Participants are taught by the group facilitator to recognize the unique qualities that a child exhibits as an expression of his/her temperament. Intentionality, the belief that the child is consciously misbehaving, is reduced when participants recognize that a child's reactions to situations are related to his/her temperament. Participants are encouraged to reframe their perceptions with the understanding that every temperament has strengths and areas of concern. They also learn that while temperament is not amenable to change, teacher and parent responses are, and these can greatly influence a child's behavior. Optimal, adequate, and counterproductive responses are discussed. In part two, "Gaining Compliance," a number of behavior management strategies are introduced. Acceptance of a child's temperament does not imply permissiveness. Rather, participants are encouraged to apply management strategies specifically matched to a child's temperament. Finally, part three, "Giving Control," focuses on additional strategies that support children in becoming more competent when they encounter situations that are temperamentally challenging. In such instances, providing goodness of fit involves scaffolding and stretching. Scaffolding entails an assessment of the situation in relation to the child's temperament. If the situation is likely to overwhelm the child, the challenge is removed or the magnitude of its demands is minimized. However, if the child is perceived as being able to manage the situation with support, strategies are gently applied to stretch the child's emotional, attentional, or behavioral repertoire. With practice, the child can learn to self-administer such stretching strategies to enhance his/her own self-regulation. Scaffolding and stretching are supported by recent descriptive studies demonstrating children's self-regulation is to some degree malleable (Kochanska \& Aksan, 2006; Posner \& Rothbart, 2000; Rothbart \& Bates, 2006).

The children's program is conducted over the same 10 -week period as the teacher and parent programs, with each session lasting 45 minutes. The content is delivered in two parts. In the first, children learn that based on one's temperament, various situations are easy while others may be challenging. Specifically, children are introduced to four puppets that represent common temperament typologies (McClowry, 2002a, b). The children also view videotaped vignettes that demonstrate each puppet's reaction to a variety of situations. In the second part of the intervention, children interact with the puppets and with their peers to problem-solve daily dilemmas. More detailed information about the teacher, parent, and children's programs can be found in McClowry et al. (2005). 


\section{Method}

Participants and Setting

Six elementary schools with students of comparable sociodemographic characteristics in an inner city school district of a Northeastern city were partners in conducting this study. Originally, five schools were randomly assigned to either INSIGHTS (3 schools) or the Read Aloud program (2 schools). During the course of the study, one of the INSIGHTS schools had a change of principal who declined to continue hosting the program at her school. The school was replaced by another school from the district of comparable size and demographic characteristics.

The participants in the study included 151 inner city children, their parents, and teachers. Thirty-five of these children were not included in this analysis for the following reasons: the teachers and their students were not involved in the intervention concurrently (i.e., the children participated in the intervention a year or more after their teacher had completed it with students in another classroom, $n=24$ ); children moved to a different classroom during the intervention phase $(n=4)$; or the teachers did not provide any questionnaire data at baseline or at post-test, even though the child, parent, and teacher participated in the intervention $(n=7)$. This resulted in an analysis sample of 116 children and their 42 teachers. No significant differences were found between the children included in this analysis $(n=116)$ and those who were excluded $(n=35)$ on baseline variables, the age or gender of the children, or in the educational level of their parents.

The children in this analysis ranged from 5 to 9 years of age $(M=6.7, \mathrm{SD}=.81)$. Sixty-two $(53 \%)$ of the children were boys. The race/ethnicity of the children included 102 African American (88\%), 12 Hispanic, non-Black (10\%), and 2 children (2\%) who were racially mixed. Sixty-seven $(58 \%)$ of the children lived in single-parent homes, 40 (34\%) lived in a two-parent household, and 9 (8\%) respondents declined to report their family configuration. Seventy-four (64\%) were in first grade and the remaining $42(36 \%)$ were in second grade. School district reports indicated that approximately $86 \%$ of the children qualified for free or reduced lunch programs.

The teacher participants included 28 first grade and 14 second grade teachers (40 female, 2 male) in regular education classrooms. Teachers reported their race/ethnicity as follows: 35 African American (83\%), 3 Hispanic, non-Black (7\%), 2 Caucasian (5\%), and 2 Asian (5\%).

\section{Measures}

The Sutter-Eyberg Student Behavior Inventory (SESBI) was used to measure teachers' reports of disruptive classroom behavior (Eyberg \& Pincus, 1999). The SESBI is the teacher version of the Eyberg Child Behavior Inventory (Eyberg, 1992) and has been widely used in prevention intervention and treatment (Burns \& Patterson, 2001). The tool consists of 36 items that are rated along two scales: (1) a 7-point Likert-type occurrence scale on which the teacher reports how often the behavior currently occurs, and (2) a yes-no problem scale on which the teacher indicates whether or not the child's behavior is problematic. Eyberg and Pincus cited an internal consistency of .97 and .96 in an African American sample for the occurrence and problem scales, respectively. In this study, the alphas were .98 and .97 , respectively.

The Teacher's Rating Scale of Child's Actual Competence and Social Acceptance (TRS) was developed by Harter (1985) to assess teachers' perceptions of children's competence. The measure includes 13 Likert-type items that form three subscales (cognitive competency, physical competency, and peer acceptance) and is similar in content to the widely used Pictorial Scale of Perceived Competence and Social Acceptance for Young Children (Harter \& Pike, 1984). Although the TRS is not as frequently used as the children's version of the measure, Cole, Gondoli, \& Peeke (1998) found that the tool also supported the theoretical structure proposed by Harter and had adequate reliability, discriminant and convergent validity. The alphas for the subscales ranged from .87 to .94 in the current study.

\section{Procedures}

Prior to beginning the study, several months were spent initiating partnerships with the administrators, principals, teachers, and parents of an inner city school district. A series of focus groups and pilot studies were conducted to develop INSIGHTS as a culturally and developmentally appropriate intervention (McClowry \& Galehouse, 2002). Specifically, community stakeholders assessed the curriculum, the research protocol, and the cultural appropriateness and readability of the assessment instruments. In addition, temperament and cultural experts conducted a validity assessment of the relevance and developmental appropriateness of the program content. Visual materials including puppets, professionally produced videotaped content vignettes, and a detailed procedure manual were subsequently created (McClowry, 2002a, b).

Stakeholders were informed from the onset that participating schools would be randomly assigned to receive either INSIGHTS or the Read Aloud program. After randomization, classroom teachers were the first to be recruited. A 30-minute information session for first and second grade teachers was followed by individual invitations. When a classroom teacher consented, a variety of strategies were implemented to recruit parents: letters, 
pamphlets, telephone calls, and brief presentations at parent meetings. After a parent consented to participate, his or her child was asked to give assent. Incentives were provided to all the study participants. After the baseline data collection activities were completed, parents received $\$ 30$, teachers received $\$ 20$, and the participating children received a small gift (e.g., a book).

In preparation for conducting the intervention, INSIGHTS facilitators and puppet therapists participated in a graduate level course that covered content areas related to the program. They also received an additional 30 hours of training during which they learned how to conduct the intervention using a scripted manual for the parent and teacher sessions, and how to implement the children's sessions with puppets using drama therapy techniques.

A facilitator, assigned to each school hosting INSIGHTS, conducted the 10 weekly, 2-hour workshops for the teachers and for the parents. Teacher sessions were held after school. Parent groups were scheduled in the mornings or evenings at times that the parents designated as convenient. The facilitator at the school, assisted by a puppeteer, also conducted a 45-minute per week children's program in the classrooms of the participating teachers. Parents who were not participating in the study were given the option of having their child removed from the classroom during the children's sessions. None of the non-participating parents, however, requested that their child be removed.

Several procedures were used to assess implementation fidelity (Lane, Bocian, MacMillan, \& Gresham, 2004). Facilitators used a detailed manual and checklist that included the objectives, accompanying activities, and participant handouts for each session. Parent and teacher sessions were videotaped and subsequently reviewed by the principal investigator. Deviations from the manual and procedures, as well as issues related to the children's program, were discussed in weekly supervision meetings with the principal investigator.

Parents and teachers in the INSIGHTS program received up to $\$ 150$ if they attended all of the workshop sessions. When parents and teachers were not able to attend a group session, the facilitators made every effort to meet with them individually to cover the missed content. Teachers attended an average of 7.5 sessions $(\mathrm{SD}=2.32)$ for a $75 \%$ attendance rate. Parents attended an average of 8 sessions $(\mathrm{SD}=2.68)$ for an $83 \%$ attendance rate. Attendance for the children in the INSIGHTS classrooms was $88 \%$. No arrangements were made for missed sessions in the children's program.

In the schools that were assigned to the attention control condition, an after-school Read Aloud program was offered to the participating children over a 10 -week period. Teachers in participating schools read a different book each week and asked the children to discuss and draw pictures about the story. No make-up sessions were scheduled for children who were absent. Attendance for the children in the Read Aloud program was $80 \%$.

Following completion of the intervention phase, the questionnaires that were administered at baseline were repeated. The same incentives were given to the parents, teachers, and children.

\section{Results}

Several steps were conducted to prepare the data for analyses. Missing data were imputed using the SPSS 16.0 implementation of the EM algorithm (expectation-maximization; SPSS, Inc., 2007), a statistical technique that uses an iterative procedure to estimate missing values using maximum-likelihood estimation (McCartney, Burchinal, \& Bub, 2006; McLachlan \& Krishnan, 1997). Missing data rates for the variables in this analysis averaged less than $2 \%$ at baseline and $5.5 \%$ at post-test, which is well within acceptable limits for the use of this method of imputation (McCartney et al., 2006). Further, there were no significant group differences between families with missing versus complete data on any of the study variables. The resulting dataset was analyzed using complete data methods for the sample of 116 participants.

To identify types of disruptive classroom behaviors and to cross-validate the factor structure of the SESBI for this sample, a principal components factor analysis with varimax rotation was conducted on the occurrence items. Replicating the methodology used by Burns, Walsh and Owen (1995), the variability of the items was examined. Consistent with Burns et al. (1995), "Hits teacher" was removed because it was endorsed as occurring in only $8 \%$ of the sample. Four factors were a priori retained for rotation. The "Demands teacher attention" item was then removed because it did not have a loading of .50 on any of the factors. As shown in Table 1, the item loadings ranged from .54 to .86 and corresponded closely to the factors identified by Burns \& Owen (1990) and Burns et al. (1995). The factors were labeled: overt aggression toward others, emotionaloppositional behavior, attentional difficulties, and covert disruptive behavior. Subscales were created by averaging the items on each factor to create four occurrence subscales and four problem subscales. The alphas for the occurrence subscales ranged from .84 to .96 . The Kuder-Richardson reliability for the problem subscales ranged from .74 to .94 .

To cross-validate the factor structure of the TRS for this sample, a principal components factor analysis with varimax rotation was conducted with the criterion of eigenvalue $\geq 1$. All of the items clustered on the hypothesized subscales with factor loadings ranging from .67 to .88 . The alphas for the three subscales ranged from .87 to .94 . 
Table 1 Factor loadings of SESBI item stems

\begin{tabular}{|c|c|c|c|c|}
\hline Item number and stem & $\mathrm{OAO}$ & EOB & ATD & $\mathrm{CDB}$ \\
\hline \multicolumn{5}{|l|}{ Overt aggression toward others (OAO) } \\
\hline 20 teases/provokes & .80 & & & \\
\hline 22 verbally fights & .73 & & & \\
\hline 21 acts bossy & .73 & & & \\
\hline 23 physically fights & .71 & & & \\
\hline 19 makes noises & .69 & & & \\
\hline 5 refuses to obey until threatened & .64 & & & \\
\hline 4 does not obey rules & .62 & & & \\
\hline 36 overactive & .61 & & & \\
\hline 26 interrupts students & .59 & & & \\
\hline 30 blames others & .59 & & & \\
\hline 25 interrupts teacher & .56 & & & \\
\hline \multicolumn{5}{|l|}{ Emotional-oppositional behavior (EOB) } \\
\hline 11 cries & & .82 & & \\
\hline 8 temper tantrums & & .79 & & \\
\hline 12 pouts & & .77 & & \\
\hline 10 whines & & .76 & & \\
\hline 6 gets angry & & .73 & & \\
\hline 3 difficulty accepting criticism & & .72 & & \\
\hline 7 acts defiant & & .68 & & \\
\hline 9 sasses teacher & & .68 & & \\
\hline 2 argues about rules & & .63 & & \\
\hline 13 yells/screams & & .59 & & \\
\hline \multicolumn{5}{|l|}{ Attentional difficulties (ATD) } \\
\hline 32 difficulty staying on track & & & .86 & \\
\hline 34 fails to finish tasks & & & .83 & \\
\hline 31 easily distracted & & & .77 & \\
\hline 33 frustrated with tasks & & & .72 & \\
\hline 27 difficulty entering groups & & & .60 & \\
\hline 35 impulsive & & & .57 & \\
\hline 28 difficulty sharing materials & & & .55 & \\
\hline 1 dawdles & & & .54 & \\
\hline 29 uncooperative & & & .54 & \\
\hline \multicolumn{5}{|l|}{ Covert disruptive behavior (CDB) } \\
\hline 17 steals & & & & .74 \\
\hline 16 destroys books/objects & & & & .73 \\
\hline 15 careless with books/objects & & & & .72 \\
\hline 18 lies & & & & .59 \\
\hline$\%$ of variance & 23.98 & 22.71 & 18.70 & 8.58 \\
\hline
\end{tabular}

Note: The item "Hits teacher" was not included due to the lack of endorsement. "Demands teacher attention" was not included because it did not have a loading of .50 on any of the factors

Preliminary analyses were conducted to determine whether there were any differences at baseline between the participants in INSIGHTS and those in the Read Aloud group. Chi-square analyses revealed no significant proportional differences between the two groups in terms of children's gender, children's race/ethnicity, or parents' level of education. Likewise, $t$-tests showed no significant differences between the groups in terms of children's ages or any of the subscales of the SESBI. One significant difference, however, did emerge on the TRS: students in Read Aloud $(M=3.20, \mathrm{SD}=.58)$ were rated by their teachers as significantly higher in peer acceptance than students in INSIGHTS $(M=2.86, \mathrm{SD}=.73), t(114)=2.78$, $p=.006$.

Independent $t$-tests next examined whether boys and girls differed on measures of disruptive behavior, competence, and peer acceptance, and whether their teachers reported more difficulty managing their behavior. As shown in Table 2, there were significant differences on each of the SESBI subscales, with boys demonstrating more behavior problems than girls. In addition, teachers reported more difficultly managing their male students' overt aggression toward others, emotional-oppositional behavior, and covert disruptive behavior; no gender differences emerged for students' attentional difficulties. As also shown, no significant gender differences were found for teachers' perceptions of the students' cognitive competence, physical competence, or peer acceptance. Due to the systematic pattern of gender differences in classroom behavior problems, however, all subsequent analyses were conducted separately for boys and girls.

A repeated measures analysis of variance (ANOVA) (Tabachnick \& Fidell, 2001) was conducted for each of the SESBI occurrence subscales to determine whether primary grade students who participated in INSIGHTS compared to those in the Read Aloud attention control group exhibited significantly greater reductions in disruptive classroom behaviors from baseline to post-test. As compared to boys in the Read Aloud program, boys participating in INSIGHTS showed a significantly greater decline in overt aggression toward others, $F(1,60)=5.41, p=.02$, and exhibited less attentional difficulties over time, $F(1,60)=6.56, p=.01$. The effect size for INSIGHTS on boys' overt aggression toward others and attentional difficulties was $d=.32$ and $d=.45$, respectively. No other significant time $\times$ condition interactions were found for boys or for girls. The findings of these analyses are summarized in Table 3.

Teachers' perceptions of their own efficacy in managing students' behavior was assessed on the problem subscales of the SESBI. Responses to the problem items were dichotomous-yes or no. Each subscale score was the total number of items endorsed as "yes." Because of the dichotomous response format, a reduction from baseline to post-test on a given subscale was considered an improvement in the teacher's perceptions of her/his classroom management. A positive change from baseline to post-test was coded as a dummy variable, representing a decrease in the teacher's reported difficulty managing disruptive classroom behaviors (vs. no change or an increase). This dummy variable was then used as the dependent variable in 
Table 2 Independent $t$-tests comparing boys and girls on disruptive behavior, competence, and peer acceptance as rated by teachers

\begin{tabular}{|c|c|c|c|c|c|}
\hline & \multicolumn{2}{|c|}{ Boys $(n=62)$} & \multicolumn{2}{|c|}{ Girls $(n=54)$} & \multirow[t]{2}{*}{$t$} \\
\hline & $M$ & SD & $M$ & SD & \\
\hline \multicolumn{6}{|c|}{ Occurrence of student disruptive behavior } \\
\hline Overt aggression toward others & 3.45 & 1.69 & 2.35 & 1.32 & $3.94 * * *$ \\
\hline Emotional-oppositional behavior & 2.77 & 1.65 & 1.91 & 1.27 & $3.17 * *$ \\
\hline Attentional difficulties & 3.55 & 1.50 & 2.67 & 1.46 & $3.19 * *$ \\
\hline Covert disruptive behavior & 2.35 & 1.35 & 1.60 & 0.90 & $3.57 * * *$ \\
\hline \multicolumn{6}{|c|}{ Teacher problems managing disruptive behavior } \\
\hline Overt aggression toward others & 0.30 & 0.35 & 0.18 & 0.28 & $1.96^{*}$ \\
\hline Emotional-oppositional behavior & 0.21 & 0.33 & 0.09 & 0.23 & $2.22 *$ \\
\hline Attentional difficulties & 0.30 & 0.36 & 0.22 & 0.29 & 1.35 \\
\hline Covert disruptive behavior & 0.19 & 0.28 & 0.07 & 0.21 & $2.45^{*}$ \\
\hline \multicolumn{6}{|c|}{ Student competence and peer acceptance } \\
\hline Cognitive competence & 2.49 & 0.95 & 2.77 & 0.92 & -1.62 \\
\hline Physical competence & 3.05 & 0.60 & 3.10 & 0.62 & -0.45 \\
\hline Peer acceptance & 2.98 & 0.64 & 3.08 & 0.72 & -0.78 \\
\hline
\end{tabular}

$* p<.05, * * p<.01, * * * p<.001$

Table 3 Repeated measures ANOVA: Means and SDs of disruptive behaviors for INSIGHTS and Read Aloud students

\begin{tabular}{|c|c|c|c|c|c|}
\hline & \multicolumn{2}{|c|}{$\operatorname{INSIGHTS}(n=25)$} & \multicolumn{2}{|c|}{ Read Aloud $(n=37)$} & $F$ \\
\hline \multicolumn{6}{|l|}{ Boys } \\
\hline Overt aggression toward others & $4.03(1.76)$ & $3.57(1.43)$ & $3.06(1.53)$ & $3.11(1.64)$ & $5.41 *$ \\
\hline Emotional-oppositional behavior & $3.26(1.86)$ & $3.09(1.56)$ & $2.44(1.42)$ & $2.51(1.51)$ & 0.78 \\
\hline Attentional difficulties & $4.25(1.30)$ & $3.61(1.31)$ & $3.07(1.45)$ & $3.05(1.52)$ & $6.56^{* *}$ \\
\hline Covert disruptive behavior & $2.68(1.59)$ & $2.60(1.61)$ & $2.13(1.12)$ & $2.06(1.14)$ & 0.00 \\
\hline & \multicolumn{2}{|c|}{$\operatorname{INSIGHTS}(n=33)$} & \multicolumn{2}{|c|}{ Read Aloud $(n=21)$} & \\
\hline \multicolumn{6}{|l|}{ Girls } \\
\hline Overt aggression toward others & $2.46(1.41)$ & $2.35(1.27)$ & $2.18(1.18)$ & $2.12(1.13)$ & 0.05 \\
\hline Emotional-oppositional behavior & $2.03(1.31)$ & $2.11(1.22)$ & $1.72(1.22)$ & $1.68(1.03)$ & 0.38 \\
\hline Attentional difficulties & $2.70(1.35)$ & $2.66(1.34)$ & $2.62(1.64)$ & $2.27(1.31)$ & 1.56 \\
\hline Covert disruptive behavior & $1.64(0.91)$ & $1.76(1.03)$ & $1.54(0.90)$ & $1.48(0.80)$ & 0.78 \\
\hline
\end{tabular}

$* p<.05, * * p<.01$

logistic regression analyses that compared teachers who participated in INSIGHTS with those whose students were in the attention control condition. As shown in Table 4, a significantly greater proportion of INSIGHTS teachers, compared to those whose students were in Read Aloud, reported fewer problems managing the emotional-oppositional behavior $\left(36 \%\right.$ versus $14 \%, \chi^{2}=4.32$, OR $=3.60$, $p=.04)$, attentional difficulties $(52 \%$ versus $22 \%$, $\left.\chi^{2}=6.15, \mathrm{OR}=3.93, p=.02\right)$, and covert disruptive behavior $\left(40 \%\right.$ versus $11 \%, \chi^{2}=7.27, \quad \mathrm{OR}=5.50$, $p=.01)$ of their male students. No significant differences were found for female students.

Logistic regression was also used to examine whether teachers' perceptions of student competence and peer acceptance were enhanced. A positive change from baseline to post-test was coded as a dummy variable, representing an increase in the teacher's perceptions of student competence and peer acceptance (vs. no change or a decrease). This dummy variable was then used as the dependent variable in logistic regression analyses that compared teachers who participated in INSIGHTS with those whose students were in the attention control condition. Analyses revealed that teachers who participated in INSIGHTS perceived their male students as more competent by post-test (see Table 5). Specifically, $72 \%$ of boys in INSIGHTS versus $30 \%$ of those in the Read Aloud program were perceived by their teachers as more cognitively competent $\left(\chi^{2}=11.01\right.$, OR $=6.08$, $p<.001$ ), and $52 \%$ versus $19 \%$ were perceived as more 
Table 4 Logistic regression analyses: Percentage of teachers reporting fewer problems managing student disruptive behavior by post-test

\begin{tabular}{|c|c|c|c|c|}
\hline & INSIGHTS $(\%)$ & Read Aloud (\%) & $\chi^{2}$ & Odds-ratio \\
\hline \multicolumn{5}{|l|}{ Boys } \\
\hline Overt aggression toward others & 40 & 22 & 2.45 & 2.42 \\
\hline Emotional-oppositional behavior & 36 & 14 & 4.32 & $3.60 *$ \\
\hline Attentional difficulties & 52 & 22 & 6.15 & $3.93 *$ \\
\hline Covert disruptive behavior & 40 & 11 & 7.27 & $5.50 * *$ \\
\hline \multicolumn{5}{|l|}{ Girls } \\
\hline Overt aggression toward others & 42 & 48 & 0.14 & 0.81 \\
\hline Emotional-oppositional behavior & 21 & 14 & 0.41 & 1.62 \\
\hline Attentional difficulties & 39 & 38 & 0.01 & 1.06 \\
\hline Covert disruptive behavior & 9 & 14 & 0.35 & 0.60 \\
\hline
\end{tabular}

$* p<.05, * * p<.01$

Table 5 Logistic regression analyses: Percentage of students receiving higher teacher ratings of competence and peer acceptance by post-test

\begin{tabular}{|c|c|c|c|c|}
\hline & INSIGHTS (\%) & Read Aloud (\%) & $\chi^{2}$ & Odds-ratio \\
\hline \multicolumn{5}{|l|}{ Boys } \\
\hline Cognitive competence & 72 & 30 & 11.01 & $6.08 * * *$ \\
\hline Physical competence & 52 & 19 & 7.46 & $4.64 * *$ \\
\hline Peer acceptance & 48 & 32 & 1.52 & 1.92 \\
\hline \multicolumn{5}{|l|}{ Girls } \\
\hline Cognitive competence & 46 & 48 & 0.02 & 0.92 \\
\hline Physical competence & 55 & 33 & 2.36 & 2.40 \\
\hline Peer acceptance & 55 & 43 & 0.70 & 1.60 \\
\hline
\end{tabular}

$* * p<.01, * * * p<.001$

physically competent $\left(\chi^{2}=7.46, \mathrm{OR}=4.64, p=.01\right)$. There were no significant changes in teachers' perceptions of boys' peer acceptance, or in teachers' perceptions of girls' competence or peer acceptance.

\section{Discussion}

This study examined the efficacy of INSIGHTS in reducing teacher-reported student disruptive classroom behavior, improving teachers' classroom management, and enhancing student competence. It was anticipated that INSIGHTS would be especially effective for boys for two interrelated reasons. Overall, boys exhibit more behavior problems in the classroom setting than do girls (Kellam et al., 1998; Molins \& Clopton, 2002), and children with higher levels of behavioral problems are the most likely to benefit from intervention (Wilson et al., 2001, 2003). At baseline, male students in this study were rated by their teachers as significantly higher than females on all of the disruptive classroom behavior subscales: overt aggression toward others, emotional-oppositional behavior, attentional difficulties, and covert disruptive behavior. Teachers also reported more difficultly managing their male students' disruptive behavior (with the exception of attentional difficulties). These findings are in accord with meta-analyses that document student gender differences in teachers' reported management of problem behavior (Jones \& Dindia, 2004; Kelly, 1988).

The first hypothesis predicted that INSIGHTS, as compared to the Read Aloud attention control condition, would reduce disruptive classroom behavior. INSIGHTS was efficacious in reducing boys' overt aggression toward others $(d=.32)$ and their attentional difficulties $(d=.45)$. These effect sizes compare favorably with findings from other school-based interventions. In meta-analyses of school-based prevention programs, average effect sizes of .05 and .13 were found for interventions in early elementary grades (Wilson et al., 2001) and high risk populations (Wilson et al., 2003), respectively. The content of the INSIGHTS curriculum provides teachers with a framework for understanding their students' behavior and selecting temperament-based strategies for classroom management. Teachers are taught to use scaffolding and stretching strategies for students whose temperaments are low in task persistence, a dimension of temperament often associated with attentional problems. Teachers also learn strategies for aggressive children, who often have temperaments that are 
high in negative reactivity; counterproductive responses only exacerbate their problem behavior. Thus, teachers learn more effective ways to respond which, in turn, may account for the reduction in boys' disruptive classroom behavior.

The second hypothesis focused on teachers' management of students' disruptive behavior. Following intervention, teachers in INSIGHTS, compared to those in the Read Aloud program, were 3.6 times more likely to report fewer problems managing boys' emotional-oppositional behavior, 3.9 times more likely to report fewer problems with their attentional difficulties, and 5.5 times more likely to report less difficulty handling their covert disruptive behavior. These findings support the assertion that teachers perceived themselves as more efficacious in handling disruptive classroom behavior. Self-efficacy is the perception that one is capable of handling a situation (Bandura, 1991). Teachers who perceive themselves as efficacious in classroom management are more adept at managing challenging student behaviors (Baker, 2005).

The final hypothesis predicted that INSIGHTS would enhance teacher perceptions of student competence and peer acceptance. Following intervention, teachers in INSIGHTS, compared to those in the Read Aloud program, were 6 times more likely to perceive their male students as cognitively competent and 4.6 times more likely to see them as physically competent. One of the major tenets of INSIGHTS is reframing, which entails changing one's viewpoint about a situation so that the "facts" are reinterpreted in a way that supports a different perspective (Nardone \& Watzlawick, 1993). Reframing softens an individual's logic and permits a more positive reinterpretation. During their sessions, teachers discuss how each type of student temperament has strengths and areas of concern. Greater sensitivity to the child and a more positive perspective by the teachers-particularly of their male students-may have resulted from such reframing exercises.

Other intervention studies also have found greater efficacy for boys as compared to girls (Barrera et al., 2002; Flay, Graumlich, Segawa, Burns, Holliday, \& Aban, 2004; Komro et al., 2004). The lack of efficacy findings among female students may be accounted for by several factors. One explanation may rest in the lower average levels of disruptive behavior exhibited by girls, which may have produced a floor effect. Another reason may be related to the type of behavior problems that were measured in this study. Behavioral inventories such as the SESBI focus solely on disruptive behavior without measuring other types of aggression (Cole et al., 1998). Several studies suggest that while boys and girls may exhibit similar rates of behavior problems, their expressions vary in form. Specifically, boys are more physically and verbally aggressive while girls are more likely to demonstrate relational aggression, which includes behaviors that threaten or damage relationships (Crick \& Grotpeter, 1995; Young, Boye, \& Nelson, 2006).

Strengths, Limitations, and Implications for Future Research

The results of the analyses presented in this paper should be examined in light of the strengths and limitations of the overall study. A notable strength was the careful examination of the SESBI. Using the criteria outlined by Burns et al. (1995), the data in this study replicated the types of disruptive behaviors they identified: overt aggression toward others, emotional-oppositional behavior, attentional difficulties, and covert disruptive behavior. The replication of these factors is of particular note since the Burns study included a sample of children who were from a rural college town and ranged from kindergarten through fifth grade. The identified types of disruptive behaviors can assist other researchers in interpreting their own results, particularly as they pertain to boys in the primary grades.

Another strength of this study is the comparison of the INSIGHTS intervention with a Read Aloud program that served as an attention control condition. Many classroom intervention studies do not include a comparison or a control group (Evertson \& Weinstein, 2006). In this study, an attention control Read Aloud program was used as the comparison. The advantage to having an attention control condition was that all children, even those in the "control" schools, received some type of intervention. The parents and teachers in the control schools, however, did not receive any intervention-a noteworthy limitation of the study design.

Several other limitations should be addressed along with their related suggestions for future research. The first is related to the exclusive reliance on teacher reports, which may be limited by their potential for bias. Other prevention studies have found that while observations indicated a reduction of aggressive behavior among primary grade students, teacher reports were not sufficiently sensitive in detecting such changes (Catalano, Mazza, Harachi, Abbot, Haggerty, \& Fleming, 2003; Frey, Hirschstein, \& Guzzo, 2000). Future studies should thus include multi-method approaches to assessing student disruptive behavior and teacher classroom management, such as the incorporation of observational techniques. In addition, teacher reports in subsequent grades may offer more objectivity and could be used to gauge the long-term efficacy of INSIGHTS.

A second limitation is related to the small number of students from each classroom who participated in the study. Although a number of recruitment strategies were used, the study participants averaged less than 3 students per classroom. Consequently, it is not possible to determine whether the children and their parents were representative of the 
larger population. Moreover, the small number of children in the study did not permit for an examination of the clinical significance of changes in teachers' perceptions of their own efficacy. Clinical significance refers to the practical or applied effects of an intervention (Harman, Manning, Lurie, \& Liu, 2001; Kazdin, 2003). One way to assess clinical significance is to examine changes between dysfunctional and normative levels on a given outcome. Based on their standardization of the SESBI, Eyberg and Pincus (1999) reported that scores of 19 and above on the problem scale fall within the dysfunctional or severe range. In the current study sample, sixteen percent $(n=19)$ of the problem scale scores met this criterion: 12 pertained to teachers who participated in INSIGHTS and 7 to teachers in Read Aloud. An exploratory analysis revealed that of these, $58 \%$ were no longer in the severe range at post-test in INSIGHTS, compared to $29 \%$ in Read Aloud. An additional 29\% in Read Aloud went from normative levels at baseline to severe at post-test. These small cell sizes, however, prohibit conducting a more definitive assessment of clinical significance.

Another limitation is related to intervention fidelity. Although procedures were implemented to assess the content and process fidelity of the INSIGHTS intervention, no systematic evaluation was conducted to ensure participant comprehension or use of the treatment skills (Bellg, Resnick, Minicucci, Ogedegbe, Ernst, \& Borrelli, 2004).

Finally, INSIGHTS is a comprehensive intervention with teacher, parent, and classroom components. Future efforts should be directed at examining whether the same children benefit at home and at school, and whether one component is adequate to achieve positive changes in children's disruptive behavior and social competencies.

\section{Implications for Classroom Management and Social Policy}

Effective classroom management is a major concern for teachers who rank classroom discipline as their biggest problem (Ingersoll, 2003). During the 10 weeks of the INSIGHTS program, teachers are encouraged to implement temperament-based strategies to enhance classroom management. Following each session, teachers reported on their overall satisfaction with the information that was presented, the videotaped vignettes, the skill level of the facilitator, and the group process. Teachers reported high satisfaction with the program: the four items, each rated on a 3 point Likert-type scale, ranged from 2.94 to 3.0.

The results presented in this paper have implications for social policy, particularly as they pertain to boys in inner city schools. Although economically disadvantaged children begin school with the same level of motivation as their more economically stable peers (Howse, Lange, Farran, \& Boyles, 2003), they demonstrate lower levels of self-regulation which compromises them both academically and behaviorally (Childs \& McKay, 2001; Howse et al., 2003; McClowry, 2002a; Miech, Essex, \& Goldsmith, 2001). Disruptive student behavior in the primary grades has long-term ramifications. As documented by Kellam et al. (1998), boys who were disruptive in the first grade and were in classrooms in which students displayed moderate to high levels of aggression were 2.5 times more likely to be aggressive in middle school than those in first grade classrooms with less aggressive students. Moreover, person-centered analyses have demonstrated that the level of physical aggression that boys exhibit in early childhood is stable (O'Connor, Dearing, $\&$ Collins, in press); high levels of such behavior are precursors for delinquency in adolescence (Broidy et al., 2003).

Aggressive behavior is also related to special education placement. While academic issues are the most frequently cited reason for such placement, the majority of children referred to special education-which disproportionately includes more boys than girls-also exhibit disruptive behavior problems (Abidin \& Robinson, 2002; Shinn, Walker, \& Stoner, 2002). Unnecessary placement in special education can have dire repercussions: only $13 \%$ of special education students in the United States are eventually declassified and returned to regular education classrooms (Advocates for Children, 2005). Further, few students in special education graduate from high school; without a high school diploma, opportunities for employment are limited. High school drop-outs are over-represented among those who require government assistance, serve jail sentences, and have children who often repeat the same cycle of misfortune (Barton, 2005).

In contrast, preventive interventions in the elementary grades can have enduring effects as reported in recent longitudinal studies (Hawkins, Smith, Hill, Kosterman, Catalano, \& Abbott, 2007; Kellam et al., 2008). Students who participated in elementary school-based interventions, compared to those in control schools, had better mental health as young adults and more positive functioning across school and work domains.

Associations between positive teacher-student relationships and effective classroom management support the need for preventive interventions that enhance such processes (O'Connor, in press). INSIGHTS appears to be a promising temperament-based prevention program for children who are at risk for disruptive disorders and for the teachers who teach them.

Acknowledgments This manuscript was primarily supported by funding from the National Institute of Nursing Research (R01NR4781).

Open Access This article is distributed under the terms of the Creative Commons Attribution Noncommercial License which permits any noncommercial use, distribution, and reproduction in any medium, provided the original author(s) and source are credited. 


\section{References}

Abidin, R. R., \& Robinson, L. L. (2002). Stress, biases, or professionalism: What drives teachers' referral judgments of students with challenging behaviors? Journal of Emotional and Behavioral Disorders, 10, 204-213.

Advocates for Children. (2005). Leaving school empty handed. New York: Author.

Baker, P. H. (2005). Managing student behavior: How ready are teachers to meet the challenge? American Secondary Education, 33(3), 51-64.

Bandura, A. (1991). Social cognitive theory of self-regulation. Organizational Behavior and Human Decision Processes, 50, 248-268.

Barrera, M. J., Biglan, A., Taylor, T. K., Gunn, B. K., Smolkowski, K., Black, C., et al. (2002). Early elementary school intervention to reduce conduct problems: A randomized trial with Hispanic and non-Hispanic children. Prevention Science, 3, 83-94.

Barth, J. M., Dunlap, S. T., Dane, H., Lochman, J. E., \& Wells, K. C. (2004). Classroom environment influences on aggression, peer relations, and academic focus. Journal of School Psychology, 42, 115-133.

Barton, P. E. (2005). One-third of a nation: Rising dropout rates and declining opportunities. Princeton, NJ: Educational Testing Service.

Bellg, A. J., Resnick, B., Minicucci, D. S., Ogedegbe, G., Ernst, D., \& Borrelli, B. (2004). Enhancing treatment fidelity in health behavior change studies: Best practices and recommendations from the NIH behavior change consortium. Health Psychology, 23, 443-451.

Bramlett, R. K., Scott, P., \& Rowell, R. K. (2000). A comparison of temperament and social skills in predicting academic performance in first graders. Special Services in the Schools, 16, 147-158.

Broidy, L. M., Nagin, D. S., Tremblay, R. E., Bates, J. E., Brame, B., Dodge, K. A., et al. (2003). Developmental trajectories of childhood disruptive behaviors and adolescent delinquency: A six-site, cross-national study. Developmental Psychology, 39, 222-245.

Burns, G. L., \& Owen, S. M. (1990). Disruptive behaviors in the classroom: Initial standardization data on a new teacher rating scale. Journal of Abnormal Child Psychology, 18, 515-525.

Burns, G. L., \& Patterson, D. R. (2001). Normative data on the Eyberg Child Behavior Inventory and Sutter-Eyberg Student Behavior Inventory: Parent and teacher rating scales of disruptive behavior problems in children and adolescents. Child \& Family Behavior Therapy, 23(1), 15-28.

Burns, G. L., Walsh, J. A., \& Owen, S. M. (1995). Twelve-month stability of disruptive classroom behavior as measured by the Sutter-Eyberg Student Behavior Inventory. Journal of Clinical Child Psychology, 24, 453-462.

Catalano, R. F., Berglund, M. L., Ryan, J. A., Lonczak, H. S., \& Hawkins, J. D. (2002). Positive youth development in the United States: Research findings on evaluations of positive youth development programs. Prevention and Treatment, 5(15), 1-111.

Catalano, R. F., Mazza, J. J., Harachi, T. W., Abbot, R. D., Haggerty, K. P., \& Fleming, C. B. (2003). Raising healthy children through enhancing social development in elementary schools: Results after 1.5 years. Journal of School Psychology, 41, 143-164.

Chess, S., \& Thomas, A. (1984). Origins and evolution of behavior disorders. Cambridge, MA: Harvard University Press.

Childs, G., \& McKay, M. (2001). Boys starting school disadvantaged: Implications from teachers' rating of behaviour and achievement in the first two years. British Journal of Educational Psychology, $71,303-314$
Coie, J. D., \& Dodge, K. A. (1998). Aggression and antisocial behavior. In W. Damon \& N. Eisenberg (Eds.), Handbook of child psychology (3rd ed., Vol. 3, pp. 779-862). Hoboken, NJ: Wiley.

Cole, D. A., Gondoli, D. M., \& Peeke, L. G. (1998). Structure and validity of parent and teacher perceptions of children's competence: A multitrait-multimethod-multigroup investigation. Psychological assessment, 10, 241-249.

Conduct Problems Prevention Research Group. (2002). Evaluation of the first 3 years of the Fast Track prevention trial with children at high risk for adolescent conduct problems. Journal of Abnormal Child Psychology, 30, 19-36.

Crick, N. R., \& Grotpeter, J. K. (1995). Relational aggression, gender, and social-psychological adjustment. Child Development, 66(3), 710-722.

Dolan, L. J., Kellam, S. G., Brown, C. H., Werthamer-Larsson, L., Rebok, G. W., Mayer, L. S., et al. (1993). The short-term impact of two classroom-based preventive interventions on aggressive and shy behaviors and poor achievement. Journal of Applied Developmental Psychology, 14, 317-345.

Dubrow, E. F., \& Ioppolito, M. F. (1994). Effects of poverty and quality of the home environment on changes in the academic and behavioral adjustment of elementary school children. Journal of Clinical Child Psychology, 23, 401-412.

Eccles, J. S., \& Blumenfeld, P. (1985). Classroom experiences and student gender: Are there differences and do they matter? In L. C. Wilkinson \& C. B. Marrett (Eds.), Gender influences in classroom interaction (pp. 79-114). Orlando, FL: Academic Press, Inc.

Evertson, C. M., \& Weinstein, C. S. (Eds.). (2006). Handbook of classroom management: Research, practice, and contemporary issues. Mahwah, NJ: Lawrence Erlbaum Associates.

Eyberg, S. (1992). Parent and teacher behavior inventories for the assessment of conduct problems in children. In L. VandeCreek, S. Knapp, \& T. Jackson (Eds.), Innovations in clinical practice: A source book (Vol. 11, pp. 261-270). New York: Wiley.

Eyberg, S., \& Pincus, D. (1999). Eyberg Child Behavior Inventory and Sutter-Eyberg Behavior Inventory: Professional manual. Odessa, FL: Psychological Assessment Resources.

Flay, B. R., Graumlich, S., Segawa, E., Burns, J. L., Holliday, M. Y., \& Aban, A. (2004). Effects of two prevention programs on high risk behaviors among African American youth: A randomized trial. Archives of Pediatrics and Adolescent Medicine, 158, 377-384.

Frey, K. S., Hirschstein, M. K., \& Guzzo, B. A. (2000). Second Step: Preventing aggression by promoting social competence. Journal of Emotional and Behavioral Disorders, 8, 102-112.

Greenberg, M. T., Weissberg, R. P., O’Brien, M. U., Zins, J. E., Fredericks, L., Resnik, H., et al. (2003). Enhancing school-based prevention and youth development through coordinated social, emotional, and academic learning. American Psychologist, 58, 466-474

Guerin, D. W., Gottfried, A. W., Oliver, P. H., \& Thomas, C. W. (2003). Temperament: Infancy through adolescence. New York: Kluwer.

Guerra, N. G., \& Smith, E. P. (Eds.). (2006). Preventing youth violence in a multicultural society. Washington, DC: American Psychological Society.

Harman, J. S., Manning, W. G., Lurie, N., \& Liu, C. (2001). Interpreting results in mental health research. Mental Health Services Research, 3, 91-96.

Harter, S. (1985). The self-perception profile for children. Denver, CO: University of Denver. Unpublished manual.

Harter, S., \& Pike, R. (1984). The pictorial scale of competence and social acceptance for young children. Child Development, 55, 1969-1982. 
Hawkins, J. D., Smith, B. H., Hill, K. G., Kosterman, R., Catalano, R. F., \& Abbott, R. D. (2007). Promoting social development and preventing health and behavior problems during the elementary grades: Results from the Seattle social development project. Victims and Offenders, 2, 161-181.

Howse, R. B., Lange, G., Farran, D. C., \& Boyles, C. D. (2003). Motivation and self-regulation as predictors of achievement in economically disadvantaged young children. The Journal of Experimental Education, 71, 151-174.

Ingersoll, R. M. (2003). Is there really a teacher shortage? (Document R-03-4). Seattle, WA: University of Washington: Center for the Study of Teaching and Policy.

Institute of Medicine. (1994). Reducing risks for mental disorders: Frontiers for preventive intervention research. Washington DC: National Academy Press.

Jones, S. M., \& Dindia, K. (2004). A meta-analytic perspective on sex equity in the classroom. Review of Educational Research, 74(4), $443-471$.

Kazdin, A. E. (2003). Clinical significance measuring whether the interventions make a difference. In A. E. Kazdin (Ed.), Methodological issues \& strategies in clinical research (3rd ed., pp. 691-710). Washington DC: American Psychological Association.

Kellam, S. G., Brown, C. H., Poduska, J., Ialongo, N. S., Wang, W., Toyinbo, P., et al. (2008). Effects of a universal classroom behavior management program in first and second grades on young adult behavioral, psychiatric, and social outcomes. Drug and Alcohol Dependence, 95S, S5-S28.

Kellam, S. G., Ling, X., Merisca, R., Brown, C. H., \& Ialongo, N. (1998). The effect of the level of aggression in the first grade classroom on the course and malleability of aggressive behavior into middle school. Development and Psychopathology, 10, 165-185.

Kelly, A. (1988). Gender differences in teacher-pupil interactions: A meta-analytic review. Research in Education, 39, 1-23.

Keogh, B. K. (1994). Temperament and teachers' view of teachability. In W. B. Carey \& S. C. McDevitt (Eds.), Prevention and early intervention: Individual differences as risk factors for the mental health of children. Philadelphia: Brunner/Mazel.

Keogh, B. K. (2003). Temperament in the classroom: Understanding individual differences. Baltimore, MD: Brookes.

Kochanska, G., \& Aksan, N. (2006). Children's conscience and selfregulation. Journal of Personality, 74(6), 1587-1617.

Komro, K. A., Perry, C. L., Veblen-Mortenson, S., Stigler, M. H., Bosma, L. M., Munson, K. A., et al. (2004). Violence-related outcomes of the DARE plus project. Health Education \& Behavior, 31, 335-354.

Lane, K. L., Bocian, K. M., MacMillan, D. L., \& Gresham, F. M. (2004). Treatment integrity: An essential-but often forgottencomponent of school-based interventions. Preventing School Failure, 48(3), 36-43.

Lerner, J. V., Lerner, R. M., \& Zabski, S. (1985). Temperament and elementary school children's actual and rated academic performance: A test of a "goodness-of-fit" model. Journal of Child Psychology and Psychiatry, 26, 125-136.

Masten, A. S., Roisman, G. I., Long, J. D., Burt, K. B., Obradović, J., Riley, J. R., et al. (2005). Developing cascades: Linking academic achievement to externalizing and internalizing symptoms over 20 years. Developmental Psychology, 41, 733-746.

McCartney, K., Burchinal, M. R., \& Bub, K. L. (2006). Best practices in quantitative methods for developmentalists. Monographs of the Society for Research in Child Development, 71(3), 1-145.

McClowry, S. G. (2002a). The temperament profiles of school-age children. Journal of Pediatric Nursing, 17, 3-10.

McClowry, S. G. (2002b). Transforming temperament profile statistics into puppets and other visual media. Journal of Pediatric Nursing, 17, 11-17.
McClowry, S. G. (2003). Your child's unique temperament: Insights and strategies for responsive parenting. Champaign, IL: Research Press.

McClowry, S. G., \& Galehouse, P. (2002). A pilot study conducted to plan a temperament-based parenting program for inner-city families. Journal of Child \& Adolescent Psychiatric Mental Health Nursing, 15, 97-104.

McClowry, S. G., Rodriguez, E. T., \& Koslowitz, R. (2008). Temperament-based intervention: Re-examining goodness of fit. European Journal of Developmental Science, 2, 120-135.

McClowry, S. G., Snow, D. L., \& Tamis-LeMonda, C. S. (2005). An evaluation of the effects of INSIGHTS on the behavior of inner city primary school children. Journal of Primary Prevention, 26, 567-584.

McLachlan, G. J., \& Krishnan, T. (1997). The EM algorithm and extensions. New York, NY: Wiley.

Miech, R., Essex, M. J., \& Goldsmith, H. H. (2001). Socioeconomic status and the adjustment to school: The role of self-regulation during early childhood. Sociology of Education, 74(2), 102-120.

Molins, N. C., \& Clopton, J. R. (2002). Teachers' reports of the problem behavior of children in their classrooms. Psychological Reports, 90, 157-164.

Nardone, G., \& Watzlawick, P. (1993). The art of change. San Francisco, CA: Jossey-Bass.

Nelson, B., Martin, R. P., Hodge, S., Havill, V., \& Kamphaus, R. (1999). Modeling the prediction of elementary school adjustment from preschool temperament. Personality and Individual Differences, 26, 687-700.

O'Connor, E. (in press). Teacher-child relationships as dynamic systems. Journal of School Psychology.

O'Connor, E. \& Dearing, E., \& Collins, B. (in press). Teacher-child relationship trajectories: Predictors of behavior problem trajectories and mediators of child and family factors. American Educational Research Journal.

Posner, M. I., \& Rothbart, M. K. (2000). Developing mechanisms of self-regulation. Development and Psychopathology, 12, $427-441$

Prior, M., Sanson, A., Smart, D., \& Oberklaid, F. (2000). Pathways from infancy to adolescence: Australian temperament project 1983-2000. Melbourne, Australia: Australian Institute of Family Studies.

Pullis, M., \& Cadwell, J. (1982). The influence of children's temperament characteristics on teachers' decision strategies. American Educational Research Journal, 19, 165-181.

Rothbart, M. K., \& Bates, J. E. (2006). Temperament in children's development. In W. Damon \& R. Lerner (Eds.), Handbook of child psychology (6th ed., Vol. 3, pp. 99-166). New York: Wiley.

Schaeffer, C. M., Petras, H., Ialongo, N., Masyn, K. E., Hubbard, S., Poduska, J., et al. (2006). A comparison of girls' and boys' aggressive-disruptive behavior trajectories across elementary school: Prediction to young adult antisocial outcomes. Journal of Consulting and Clinical Psychology, 74, 500-510.

Shinn, M. R., Ramsey, E., Walker, H. M., Stieber, S., \& O’Neill, R. (1987). Antisocial behavior in school settings: Initial differences in an at-risk and normal population. The Journal of Special Education, 21, 69-84.

Shinn, M. R., Walker, H. M., \& Stoner, G. (Eds.). (2002). Interventions for academic and behavior problems II: Preventive and remedial approaches. Bethesda, MD: National Association of School Psychologists.

SPSS. (2007). Expectation-maximization (Version 16.0). Chicago, IL: SPSS, Inc.

Tabachnick, B. G., \& Fidell, L. S. (2001). Using multivariate statistics (4th ed.). Needham Heights, MA: Allyn \& Bacon.

Tremblay, R. E., Pihl, R. O., Vitaro, F., \& Dobkin, P. L. (1994). Predicting early onset of male antisocial behavior from preschool behavior. Archives of General Psychiatry, 51, 732-739. 
Wilson, D. B., Gottfredson, D. C., \& Najaka, S. S. (2001). Schoolbased prevention of problem behaviors: A meta-analysis. Journal of Quantitative Criminology, 17, 247-272.

Wilson, S. J., Lipsey, M. W., \& Derzon, J. H. (2003). The effects of school-based intervention programs on aggressive behavior: A meta-analysis. Journal of Consulting and Clinical Psychology, 71, 136-149.

Young, E. L., Boye, A. E., \& Nelson, D. A. (2006). Relational aggression: Understanding, identifying, and responding in schools. Psychology in the Schools, 43, 297-312. 